\title{
Copy number variants and placental abnormalities in stillborn fetuses: a secondary analysis of the Stillbirth Collaborative Research Network study
}

Tsegaselassie Workalemahu ${ }^{1}$, Susan Dalton ${ }^{1}$, Amanda Allshouse ${ }^{1}$, Andrew Carey ${ }^{1}$, Jessica Page $^{2}$, Nathan Blue ${ }^{1}$, Vanessa Thorsten ${ }^{3}$, Robert Goldenberg ${ }^{4}$, Halit Pinar ${ }^{5}$, Uma Reddy ${ }^{6}$, and Robert Silver (USA) ${ }^{1}$

${ }^{1}$ University of Utah Health

${ }^{2}$ Intermountain Medical Center

${ }^{3}$ RTI International

${ }^{4}$ Columbia University

${ }^{5}$ Brown University Warren Alpert Medical School

${ }^{6}$ Yale University School of Medicine

February 12, 2022

\begin{abstract}
Objective To examine the association of DNA copy number variants (CNVs) with pathologic placental lesions (PPLs) in stillborn fetuses. Design A secondary analysis of stillbirth cases in the Stillbirth Collaborative Research Network case-control study. Setting Multicenter, 59 hospitals in 5 geographic regions in the USA. Population 387 stillbirth cases (2006-2008). Methods Using standard definitions, PPLs were categorized by type including maternal and fetal vascular, inflammatory and immune/idiopathic lesions. Using single-nucleotide polymorphism array, CNVs of at least $500 \mathrm{~kb}$ were detected. CNVs were classified into two groups: normal, defined as no CNVs>500 kb or benign CNVs, and abnormal, defined as pathogenic or variants of unknown clinical significance. Main outcome measures The proportions of abnormal CNVs and normal CNVs were compared between stillbirth cases with and without PPLs using the Wald Chi-squared test. Results Of 387 stillborn fetuses, 327 (84.5\%) had maternal vascular PPLs and 60 (15.6\%) had abnormal CNVs. Maternal vascular PPLs were more common in stillborn fetuses with abnormal CNVs compared with those with normal CNVs $(81.7 \%$ vs. $64.2 \% ; \mathrm{p}=0.008)$. The proportions of fetal vascular, maternal/fetal inflammatory, and immune/idiopathic PPLs were similar among stillborn fetuses with abnormal CNVs compared to those with normal CNVs. Pathogenic CNVs in stillborn fetuses with maternal vascular PPLs spanned several genes with known relevant mechanisms. Conclusions Abnormal placental/fetal CNVs were associated with maternal vascular PPLs in stillborn fetuses. Findings may provide insight on the mechanisms of specific genetic abnormalities associated with placental dysfunction and stillbirth.
\end{abstract}

Copy number variants and placental abnormalities in stillborn fetuses: a secondary analysis of the Stillbirth Collaborative Research Network study

Workalemahu, Tsegaselassie PhD, MS${ }^{1}$; Dalton, Susan $\mathrm{MD}^{1}$; Allshouse, Amanda $\mathrm{MS}^{1}$; Carey, Andrew Z. $\mathrm{MD}^{1}$; Page, Jessica M. MD, MSCI ${ }^{1,2}$; Blue, Nathan R. MD ${ }^{1}$; Thorsten, Vanessa $\mathrm{MPH}^{3,4}$; Goldenberg, Robert L. MD ${ }^{5}$; Pinar, Halit MD ${ }^{6}$; Reddy, Uma M. MD ${ }^{7}$; Silver, Robert M. MD ${ }^{1,2}$

\section{Affiliations :}

${ }^{1}$ University of Utah Health, Salt Lake City, UT; ${ }^{2}$ Intermountain Healthcare, Salt Lake City, UT; ${ }^{3}$ Columbia 
University Medical Center, New York, NY; ${ }^{4}$ RTI International, Research Triangle Park, NC; ${ }^{5}$ Department of Obstetrics and Gynecology, Columbia University, New York, NY; ${ }^{6}$ Division of Perinatal Pathology, Brown University School of Medicine, Providence, RI; ${ }^{7}$ Obstetrics, Gynecology \& Reproductive Sciences, Yale University, New Haven, CT

Corresponding author: Tsegaselassie Workalemahu, PhD, MS, University of Utah, 30 N 1900 E, Suite 2B293, Salt Lake City, UT 84132; e-mail: tsegaselassie.workalemahu@hsc.utah.edu

This work was supported by grant funding from the Eunice Kennedy Shriver National Institute of Child Health and Human Development: U10-HD045953 Brown University, Rhode Island; U10-HD045925 Emory University, Georgia; U10-HD045952 University of Texas Medical Branch at Galveston, Texas; U10HDO45955 University of Texas Health Sciences Center at San Antonio, Texas; U10-HD045944 University of Utah Health Sciences Center, Utah; and U01-HD045954 RTI International, RTP. Secondary analysis of the primary research was supported in part by the National Center for Advancing Translational Sciences of the National Institutes of Health under Award Number 1UL01TR002538. The content is solely the responsibility of the authors and does not necessarily represent the official views of the National Institutes of Health.

Presented in part at the 35th annual scientific meeting of The Society for Pediatric and Perinatal Epidemiologic Research, June 8, 2021, Boston, Massachusetts.

\section{Abstract}

\section{Objective}

To examine the association of DNA copy number variants (CNVs) with pathologic placental lesions (PPLs) in stillborn fetuses.

\section{Design}

A secondary analysis of stillbirth cases in the Stillbirth Collaborative Research Network case-control study.

\section{Setting}

Multicenter, 59 hospitals in 5 geographic regions in the USA.

\section{Population}

387 stillbirth cases (2006-2008).

\section{Methods}

Using standard definitions, PPLs categorized by type including maternal and fetal vascular, inflammatory and immune/idiopathic lesions. Using single-nucleotide polymorphism array, CNVs of at least 500kb detected. CNVs classified into two groups: normal, defined as no CNVs $>500 \mathrm{~kb}$ or benign CNVs, and abnormal, defined as pathogenic or variants of unknown clinical significance.

\section{Main outcome measures}

The proportions of abnormal CNVs and normal CNVs compared between stillbirth cases with and without PPLs using the Wald Chi-squared test.

\section{Results}

Of 387 stillborn fetuses, $327(84.5 \%)$ had maternal vascular PPLs and 60 (15.6\%) had abnormal CNVs. Maternal vascular PPLs were more common in stillborn fetuses with abnormal CNVs compared with those with normal CNVs (81.7\% vs. $64.2 \%$; $\mathrm{p}=0.008)$. The proportions of fetal vascular, maternal/fetal inflammatory, and immune/idiopathic PPLs were similar among stillborn fetuses with abnormal CNVs compared to those with normal CNVs. Pathogenic CNVs in stillborn fetuses with maternal vascular PPLs spanned several known genes.

\section{Conclusions}


Abnormal placental/fetal CNVs were associated with maternal vascular PPLs in stillborn fetuses. Findings may provide insight on the mechanisms of specific genetic abnormalities associated with placental dysfunction and stillbirth.

\section{Keywords}

Copy number variants; placenta; stillbirth; pathologic lesions

\section{Running title}

Copy number variants and placental abnormalities.

\section{Tweetable abstract}

Abnormal copy number changes in stillborn placental and fetal DNA are associated with maternal vascular placental lesions.

\section{Introduction}

Stillbirth, most commonly defined in the U.S. as fetal death at [?]20 weeks' gestation, occurs at an estimated rate of 5.7 per 1000 births in the United States. ${ }^{1}$ The causes of stillbirth are multi-factorial, and histologic examination of the placenta, cord, or membranes can identify a cause of death in $11-65 \%$ stillbirths. $^{2,3}$ Maternal and fetal vascular lesions in the placenta are commonly associated with stillbirth. ${ }^{4-6}$ Proper function of the placenta requires uninterrupted flow of adequately oxygenated maternal and fetal blood, which is critical for fetal survival. ${ }^{7}$ Macroscopic abnormalities of the placenta, such as aberrations in shape and size, and microscopic variation in villous morphology, often reflect placental function. ${ }^{8},{ }^{9}$ Determining factors influencing placental pathological lesions will help facilitate understanding the pathogenesis, diagnosis, and treatment of stillbirth with an underlying placental etiology. ${ }^{10}$

Chromosomal assessment of the placenta and fetus with the use of single-nucleotide polymorphism (SNP) oligonucleotide microarray analysis is useful in determining causes of death in stillbirth and structural malformations in live births. ${ }^{11-13}$ Some forms of chromosomal structural abnormalities such as trisomy and monosomy are known to be associated with stillbirth. However, the relevance of other types of genetic aberrations in stillbirth cases is not well characterized, and the mechanism by which they contribute to stillbirth is not understood. Therefore, our objective was to evaluate the associations of placental and fetal CNVs with placental pathological lesions in a well characterized study of stillbirth. In addition, we discuss and highlight specific CNV deletions and duplications in genes associated with placental pathological lesions.

\section{Methods}

This study was a secondary analysis of the Stillbirth Collaborative Research Network (SCRN) study. Briefly, the SCRN study was a racially, ethnically, and geographically diverse, multicenter case-control study of stillbirth and selected live births with enrollment at the time of delivery. Recruitment occurred in 59 hospitals in 5 geographic regions throughout the US. Details about the participating hospitals and study population have been described previously. ${ }^{11,} 14$ The study was approved by the institutional review board at each clinical site and the data coordinating center. An advisory board reviewed the progress and safety of the study and written informed consent was obtained from each participant.

This work was supported by grant funding from the Eunice Kennedy Shriver National Institute of Child Health and Human Development: U10-HD045953 Brown University, Rhode Island; U10-HD045925 Emory University, Georgia; U10-HD045952 University of Texas Medical Branch at Galveston, Texas; U10HDO45955 University of Texas Health Sciences Center at San Antonio, Texas; U10-HD045944 University of Utah Health Sciences Center, Utah; and U01-HD045954 RTI International, RTP. Secondary analysis of the primary research was supported in part by the National Center for Advancing Translational Sciences of the National Institutes of Health under Award Number 1UL01TR002538. The content is solely the responsibility of the authors and does not necessarily represent the official views of the National Institutes of Health. 
Postmortem examinations and placental histologic examinations were performed by perinatal pathologists who underwent centralized training using a standardized format. Details of the placental pathologic evaluation have been previously reported. ${ }^{9}$ The INCODE cause of death classification tool was used across sites to best identify cases where a fetal or placental condition significantly contributed to the fetal death. ${ }^{15,}{ }^{16}$ In the present analysis, we included singleton stillbirth deliveries with chromosomal microarray and postmortem examinations of the fetus and placenta $(n=387)$. Of note, $98.6 \%$ of stillbirth cases in the SCRN study had placental examination completed. ${ }^{9}$.

A consensus-determined protocol was implemented to define placental pathological lesions types as maternal vascular, fetal vascular, maternal inflammatory, fetal inflammatory and immune/idiopathic lesions. ${ }^{17,}{ }^{18}$ The specific pathologic placental lesions included in each category are listed in Table S1 .

Biospecimens collected as part of the SCRN protocol included placental tissue, fetal liver, muscle, and cord blood. Sizes of placental biopsies varied, but they were as large as $1 \mathrm{~cm}^{3}$ and were stored at $-20^{0} \mathrm{C}$ from $2-5$ years prior to DNA extraction. Microarray analysis was performed at a single laboratory (Columbia University Medical Center) in 2012. Samples were analyzed using the Affymetrix Genome Wide Human SNP Array 6.0 and the Chromosome Analysis Suite, version 1.0.1, and the NetAffx annotation database, version 28 with data aligned to the Human Genome release 18. CNVs of [?]500 kb in size were detected using the SNP array. Analysis of the array data was conducted to determine aneuploidy, potential maternal-fetal contamination, and sex discordance. Classification of CNVs was based on the American College of Medical Genetics (ACMG) standards and guidelines for interpretation and reporting, with modifications as described previously. ${ }^{19}$ Due to improving resolution for determination of pathogenicity of CNVs, the number of novel structural variants is constantly increasing. ${ }^{20}$ Therefore, we implemented the latest ACMG guidelines ${ }^{21}$ in high-throughput CNV analysis to classify and update pathogenicity of CNVs previously categorized as variants of unknown clinical significance (VOUS) by using ClassifyCNV tool. ${ }^{22}$ Since VOUS CNVs should not be considered benign, we classified CNVs into two groups: abnormal CNVs (abnormal CNVs), defined as pathogenic CNVs (including aneuploidy) or VOUS, and normal CNVs (normal CNVs), defined as no CNVs $>500 \mathrm{~kb}$ or benign CNVs. ${ }^{23-25}$. As such, the abnormal CNVs and normal CNVs groups were compared in statistical analysis. In addition, study characteristics were described separately for pathogenic, VOUS and normal CNVs. We discussed the implications of the findings based on only pathogenic CNVs (excluding trisomy, monosomy, sex-chromosome and VOUS CNVs).

To test for associations of placental pathological lesions with CNV categorization, frequency and percentages were calculated within category and compared using chi-square. Other categorical measures were similarly compared by CNV category. To compare continuous measures, ANOVA was used. Data were analyzed with the use of statistical software programs: SAS version 9.4 (SAS Institute Inc), R and STATA version 15.0 (StataCorp), and ClassifyCNV tool. ${ }^{22}$

\section{Results}

Among stillbirth fetuses included in this study $(\mathrm{n}=387)$, there were $60(15.6 \%)$ with abnormal CNVs $(40$ [10.3\%] with pathogenic, and 20 [5.2\%] with VOUS CNVs) and 327 (84.5\%) with normal CNVs. Comparisons of proportions showed that stillborn fetuses with abnormal CNVs tended to be born to older women, of Hispanic ethnicity, and anomalous in comparison to those with normal CNVs (Table 1 ). Stillborn fetuses with abnormal CNVs did not differ from those with normal CNVs in regard to other socio-economic factors, parity, fetal sex, maternal chronic hypertension, preeclampsia, diabetes and gestational diabetes.

The proportion of stillborn fetuses with maternal vascular pathological lesions was higher among those with abnormal CNVs in comparison to those with normal CNVs ( $81.7 \%$ vs. $64.2 \%$; $\mathrm{p}=0.008$; Figure 1 ; Table S2 ). However, the proportions of stillborn fetuses with fetal or any (i.e. fetal or maternal) vascular pathological lesions among those with abnormal CNVs were similar in comparison to those with normal CNVs (78.3\% vs. $77.1 \% ; \mathrm{p}=0.8,95.0 \%$ vs. $90.8 \%$; $=0.3$, respectively). Furthermore, the proportions of stillborn fetuses with maternal inflammatory, fetal inflammatory, any inflammatory or immune/idiopathic placental pathological lesions among those with abnormal CNVs were similar in comparison to those with normal CNVs $(25.0 \%$ vs. 
$33.3 \% ; \mathrm{p}=0.2,11.7 \%$ vs. $15.6 \% ; \mathrm{p}=0.4,28.3 \%$ vs. $36.2 \% ; \mathrm{p}=0.2$, and $15.8 \%$ vs. $10.4 ; \mathrm{p}=0.3$, respectively). Pathogenic deletion CNVs ( $\mathrm{n}=4)$ in three stillborn fetuses and pathogenic duplication CNVs $(\mathrm{n}=4)$ in five stillborn fetuses with maternal vascular pathological lesions were identified (Table 2 ). Two stillborn fetuses with maternal vascular pathological lesions also had VOUS deletions CNVs $(n=3)$, and thirteen stillborn fetuses with maternal vascular pathological lesions had VOUS duplications CNVs ( $=14)$ (Table S3 ). Three stillborn fetuses with maternal vascular pathological lesions had multiple abnormal CNVs. Specifically, CNV 22q11.21 deletion, $16 \mathrm{p} 13.11$ duplication, and 4q32.3q35.2 and $17 \mathrm{p} 13.3$ were identified in stillborn fetuses with maternal vascular pathological lesions. The deletions and duplications each involved several genes, including the MYH11 (myosin heavy chain 11) and HNF1B (hepatocyte nuclear factor 1B) genes.

\section{Discussion}

\section{Main Findings}

Our data suggest that abnormal CNVs are associated with maternal vascular lesions in placenta of stillborn fetuses. Several pathogenic CNV deletions and duplications were identified in eight-stillborn fetuses with maternal vascular lesions, involving several genes.

\section{Interpretation}

In $88 \%$ of stillborn fetuses, a direct cause or a major contributor to death was found by histopathologic examination of the placenta, showing placental abnormalities as the most common causes of death. ${ }^{3,4,9}$ Specifically, maternal vascular supply abnormalities were more common in preterm stillbirth cases, while fetal vascular supply abnormalities were more common among term stillbirth cases. ${ }^{6,}{ }^{9}$ Moreover, a review of 120 autopsy reports of stillborn fetuses and placentas showed maternal vascular supply abnormalities in $54(51 \%)$, fetal vascular supply abnormalities in $28(26 \%)$, and inflammatory lesions in $13(12 \%)$ cases as direct or major contributors of death. ${ }^{4} 9$ Yet, many deaths in stillbirth cases remain unexplained, ${ }^{26-28}$ and our understanding of the mechanisms of placental dysfunction and stillbirth is limited.

In our study, 22q11.21 deletion, 16p13.11 duplication, and 4q32.3q35.2 and 17p13.3 deletion CNVs were identified in stillborn fetuses with maternal vascular pathological lesions. These CNVs were previously detected among stillborn fetuses in an analysis of SCRN cases, ${ }^{11}$ but not described in the context of placental pathological lesions. The deletion of 22q11.21 is pathogenic for DiGeorge/velocardiofacial syndrome. ${ }^{29}$ Pathologic placental lesions are found in DiGeorge sequence, characterized by hypoplasia in the umbilical cord arteries and widespread calcification of microthrombi in the arteries of the second and third order villous branches. ${ }^{30} \mathrm{~A}$ case study showed a copy gain of the distal region of chromosome 4 at segment 4q32.3q35.2 in a pregnant patient that presented with fetal edema and subsequent fetal loss. ${ }^{31}$ Furthermore, the duplication of $16 \mathrm{p} 13.11$ is implicated in multiple congenital anomalies in pediatric patients $(\mathrm{n}=1645) .{ }^{32}$ Mutations in MYH11 (myosin heavy chain 11) gene, among several genes in the 16p13.11 region, cause thoracic aortic aneurysms and/or dissections. ${ }^{33,}{ }^{34}$ Lastly, the $17 q 12$ recurrent deletion syndrome is characterized by structural or functional abnormalities of the kidney. ${ }^{35}$ HNF1B (Hepatocyte nuclear factor 1B) gene, among several genes in the $17 q 12$ region, is implicated in renal cysts and diabetes syndrome. ${ }^{36}$

In light of prior data, our findings suggest that 22q11.21, 4q32.3q35.2, and 16p13.11 CNVs may contribute to fetal death through placental abnormalities, both directly, as well as indirectly, by contributing to cardiac abnormalities. Interestingly, maternal/fetal vascular and inflammatory placental pathological lesions were common in pregnancies complicated by congenital heart defects ${ }^{37}$ and placental insufficiency is associated with congenital heart defects in animals and humans. ${ }^{38-40}$ Further, the placental genome plays a role in mediating fetal and maternal health. ${ }^{41-43}$ As such, $16 \mathrm{p} 13.11$ and $17 \mathrm{q} 12$ CNVs described in the context of congenital anomalies and kidney function in children and adults also suggest that genetic abnormalities in the placenta may underlie mechanisms of the developmental origins of health complications in later life. ${ }^{38,42}$ Together, these mechanisms may provide answers to causes of death in stillbirth, a basis for estimating recurrence risk, and offer insight into the developmental origins of diseases in later life.

Strengths and Limitations 
Our study has several limitations. In the present analysis, we only reported pathogenic deletions and duplications spanning several genes in stillborn fetuses with maternal vascular placental pathological lesions. While only maternal vascular placental pathological lesions were associated with CNV types in our study, the small sample size in the abnormal CNVs group may have limited power to detect associations of CNV types with other placental pathological lesions. However, to date, our study included the largest sample size of stillbirths with CNVs that had placental pathological exam completed. Another limitation is that pathologists were not blinded to stillbirth or live-birth status in the SCRN study because of the need to perform both clinical and research placental examination. Furthermore, our ability to determine pathogenicity of CNVs is limited. This will improve with increasingly larger databases of normal and abnormal phenotypes. Additionally, there are limitations to microarray-based analyses, which include inability to detect truly balanced rearrangements. Microarray-based analyses also report large chromosomal regions that span several genes, such as the ones reported in our study, making it difficult to target specific mutations in genes for clinical application. Lastly, due to lack of paternal DNA, we were not able to distinguish inherited from newly occurring CNVs in the placenta or fetus. Using higher resolution technology, such as next generation sequencing of DNA from families, future studies will be able to identify genetic mutations causing placental dysfunction and stillbirth.

One of the strengths of our study is that our cohort included a geographically, racially, and ethnically diverse study population with stillbirth. In addition, participants had a complete evaluation, including fetal postmortem examination, placental pathological analysis conducted by perinatal pathologists, and maternalfetal testing. ${ }^{44}$ These study design features provided careful phenotyping of stillbirth included in our study and maximized the validity of the present analysis.

Conclusion

Our report provides additional support for the utility of high-density microarray analysis in the detection of CNVs associated with placental pathological lesions in stillbirth cases. Further clarification of the relationship between chromosomal aberrations and placental abnormalities will be important in order to better understand the specific mechanisms leading to placental dysfunction and stillbirth. As such, these mechanisms may provide answers to causes of death in stillbirth and the basis for estimating recurrence risk.

\section{Disclosure of interests}

Eunice Kennedy Shriver National Institute of Child Health and Human Development grants were received by the institutions listed. No other conflicts of interest are reported by authors. Completed disclosure of interests forms are available to view online as supporting information.

\section{Contribution to authorship}

RMS, UMR, HP and RLG had critical roles in the conception, planning and carrying out of the study. VT, AA and TW played a critical role in data management and secondary data analysis. TW, RMS, UMR, HP, RLG, SD, AA, AZC, JMP, NRB and VT each played critical roles in conception, interpretation of the secondary data analysis and writing the manuscript. The University of Utah Institutional Review Board found this secondary analysis qualified for IRB exemption 5/9/2019 IRB\#122488 due to the de-identified nature of the data.

\section{Ethical approval}

The study was approved by the institutional review board at each clinical site and the data coordinating center. An advisory board reviewed the progress and safety of the study and written informed consent was obtained from each participant.

\section{Funding/support}

This work was supported by grant funding from the Eunice Kennedy Shriver National Institute of Child Health and Human Development: U10-HD045953 Brown University, Rhode Island; U10-HD045925 
Emory University, Georgia; U10-HD045952 University of Texas Medical Branch at Galveston, Texas; U10HDO45955 University of Texas Health Sciences Center at San Antonio, Texas; U10-HD045944 University of Utah Health Sciences Center, Utah; and U01-HD045954 RTI International, RTP. Secondary analysis of the primary research was supported in part by the National Center for Advancing Translational Sciences of the National Institutes of Health under Award Number 1UL01TR002538. The content is solely the responsibility of the authors and does not necessarily represent the official views of the National Institutes of Health.

\section{Data availability statement}

The data that support the findings of this study are avail- able from the corresponding author upon reasonable request.

\section{REFERENCES}

1. Gregory EC, Valenzuela, Claudia P, Hoyert, Donna L. Fetal Mortality: United States, 2019. National Vital Statistics Reports. 2021;70(11).

2. Ptacek I, Sebire N, Man J, Brownbill P, Heazell A. Systematic review of placental pathology reported in association with stillbirth. Placenta. 2014;35(8):552-62.

3. Page JM, Christiansen-Lindquist L, Thorsten V, Parker CB, Reddy UM, Dudley DJ, et al. Diagnostic tests for evaluation of stillbirth: results from the Stillbirth Collaborative Research Network. Obstetrics \& Gynecology. 2017;129(4):699-706.

4. Kidron D, Bernheim J, Aviram R. Placental findings contributing to fetal death, a study of 120 stillbirths between 23 and 40 weeks gestation. Placenta. 2009;30(8):700-4.

5. Pinar H, Goldenberg RL, Koch MA, Heim-Hall J, Hawkins HK, Shehata B, et al. Placental findings in singleton stillbirths. Obstetrics and gynecology. 2014;123(2 0 1):325.

6. Kulkarni VG, Sunilkumar KB, Nagaraj T, Uddin Z, Ahmed I, Hwang K, et al. Maternal and Fetal Vascular Lesions of Malperfusion in the Placentas Associated with Fetal and Neonatal Death: Results of a Prospective Observational Study. American journal of obstetrics and gynecology. 2021.

7. Ernst LM. Maternal vascular malperfusion of the placental bed. Apmis. 2018;126(7):551-60.

8. Mayhew TM, Charnock-Jones D, Kaufmann P. Aspects of human fetoplacental vasculogenesis and angiogenesis. III. Changes in complicated pregnancies. Placenta. 2004;25(2-3):127-39.

9. Pinar H, Koch MA, Hawkins H, Heim-Hall J, Shehata B, Thorsten VR, et al. The Stillbirth Collaborative Research Network (SCRN) placental and umbilical cord examination protocol. American journal of perinatology. 2011;28(10):781.

10. Redline RW. Classification of placental lesions. American journal of obstetrics and gynecology. 2015;213(4):S21-S8.

11. Reddy UM, Page GP, Saade GR, Silver RM, Thorsten VR, Parker CB, et al. Karyotype versus microarray testing for genetic abnormalities after stillbirth. New England Journal of Medicine. 2012;367(23):2185-93.

12. Wapner RJ, Martin CL, Levy B, Ballif BC, Eng CM, Zachary JM, et al. Chromosomal microarray versus karyotyping for prenatal diagnosis. New England Journal of Medicine. 2012;367(23):2175-84.

13. Dhillon R, Hillman S, Morris R, McMullan D, Williams D, Coomarasamy A, et al. Additional information from chromosomal microarray analysis (CMA) over conventional karyotyping when diagnosing chromosomal abnormalities in miscarriage: A systematic review and meta-analysis. BJOG: An International Journal of Obstetrics \& Gynaecology. 2014;121(1):11-21.

14. Parker CB, Hogue CJ, Koch MA, Willinger M, Reddy UM, Thorsten VR, et al. Stillbirth Collaborative Research Network: design, methods and recruitment experience. Paediatric and perinatal epidemiology. 2011;25(5):425-35. 
15. Dudley DJ, Goldenberg R, Conway D, Silver RM, Saade GR, Varner MW, et al. A new system for determining the causes of stillbirth. Obstetrics and gynecology. 2010;116(2 01$)$.

16. Pinar H, Koch MA, Hawkins H, Heim-Hall J, Abramowsky CR, Thorsten VR, et al. The stillbirth collaborative research network postmortem examination protocol. American journal of perinatology. 2012;29(3):187.

17. Khong TY, Mooney EE, Ariel I, Balmus NC, Boyd TK, Brundler M-A, et al. Sampling and definitions of placental lesions: Amsterdam placental workshop group consensus statement. Archives of pathology \& laboratory medicine. 2016;140(7):698-713.

18. Khong TY, Mooney EE, Nikkels PG, Morgan TK, Gordijn SJ. Pathology of the placenta: a practical guide: Springer; 2019.

19. Kearney HM, Thorland EC, Brown KK, Quintero-Rivera F, South ST. American College of Medical Genetics standards and guidelines for interpretation and reporting of postnatal constitutional copy number variants. Genetics in Medicine. 2011;13(7):680-5.

20. Pös O, Radvanszky J, Styk J, Pös Z, Buglyó G, Kajsik M, et al. Copy number variation: methods and clinical applications. Applied Sciences. 2021;11(2):819.

21. Riggs ER, Andersen EF, Cherry AM, Kantarci S, Kearney H, Patel A, et al. Technical standards for the interpretation and reporting of constitutional copy-number variants: a joint consensus recommendation of the American College of Medical Genetics and Genomics (ACMG) and the Clinical Genome Resource (ClinGen). Genetics in Medicine. 2020;22(2):245-57.

22. Gurbich TA, Ilinsky VV. ClassifyCNV: a tool for clinical annotation of copy-number variants. Scientific reports. 2020;10(1):1-7.

23. Pottinger TD, Puckelwartz MJ, Pesce LL, Robinson A, Kearns S, Pacheco JA, et al. Pathogenic and uncertain genetic variants have clinical cardiac correlates in diverse biobank participants. Journal of the American Heart Association. 2020;9(3):e013808.

24. Morales A, Hershberger RE. Variants of uncertain significance: should we revisit how they are evaluated and disclosed?: Am Heart Assoc; 2018. p. e002169.

25. Richards S, Aziz N, Bale S, Bick D, Das S, Gastier-Foster J, et al. Standards and guidelines for the interpretation of sequence variants: a joint consensus recommendation of the American College of Medical Genetics and Genomics and the Association for Molecular Pathology. Genetics in medicine. 2015;17(5):40523.

26. Korteweg FJ, Bouman K, Erwich JJH, Timmer A, Veeger NJ, Ravisé JM, et al. Cytogenetic analysis after evaluation of 750 fetal deaths: proposal for diagnostic workup. Obstetrics \& Gynecology. 2008;111(4):865-74.

27. Reddy UM, Goldenberg R, Silver R, Smith GC, Pauli RM, Wapner RJ, et al. Stillbirth classificationdeveloping an international consensus for research: executive summary of a National Institute of Child Health and Human Development workshop. Obstetrics and gynecology. 2009;114(4):901.

28. Wapner RJ, Lewis D. Genetics and metabolic causes of stillbirth. Seminars in perinatology; 2002: Elsevier; 2002. p. $70-4$.

29. Burnside RD. 22q11. 21 deletion syndromes: a review of proximal, central, and distal deletions and their associated features. Cytogenetic and Genome Research. 2015;146(2):89-99.

30. Fulcheri E, Gualco M, Delfino F, Pantarotto M. Placental lesions in a case of DiGeorge sequence. Fetal diagnosis and therapy. 2006;21(1):1-7.

31. Zhang J, Zhang B, Liu T, Xie H, Zhai J. Partial trisomy 4q and monosomy 5p inherited from a maternal translocationt $(4 ; 5)(\mathrm{q} 33 ; \mathrm{p} 15)$ in three adverse pregnancies. Molecular Cytogenetics. 2020;13(1):1-8. 
32. Ramalingam A, Zhou X-G, Fiedler SD, Brawner SJ, Joyce JM, Liu H-Y, et al. 16p13. 11 duplication is a risk factor for a wide spectrum of neuropsychiatric disorders. Journal of human genetics. 2011;56(7):541-4.

33. Takeda N, Morita H, Fujita D, Inuzuka R, Taniguchi Y, Nawata K, et al. A deleterious MYH11 mutation causing familial thoracic aortic dissection. Human Genome Variation. 2015;2(1):1-3.

34. Guo D-C, Papke CL, Tran-Fadulu V, Regalado ES, Avidan N, Johnson RJ, et al. Mutations in smooth muscle alpha-actin (ACTA2) cause coronary artery disease, stroke, and Moyamoya disease, along with thoracic aortic disease. The American Journal of Human Genetics. 2009;84(5):617-27.

35. Mitchel MW, Moreno-De-Luca D, Myers SM, Levy RV, Turner S, Ledbetter DH, et al. 17q12 recurrent deletion syndrome. GeneReviews@[Internet]. 2020.

36. Verhave JC, Bech AP, Wetzels JF, Nijenhuis T. Hepatocyte nuclear factor $1 \beta$-associated kidney disease: more than renal cysts and diabetes. Journal of the American Society of Nephrology. 2016;27(2):345-53.

37. Miremberg H, Gindes L, Schreiber L, Raucher Sternfeld A, Bar J, Kovo M. The association between severe fetal congenital heart defects and placental vascular malperfusion lesions. Prenatal diagnosis. 2019;39(11):962-7.

38. Maslen CL. Recent Advances in Placenta-Heart Interactions. Frontiers in physiology. 2018;9:735.

39. Zun Z, Zaharchuk G, Andescavage NN, Donofrio MT, Limperopoulos C. Non-invasive placental perfusion imaging in pregnancies complicated by fetal heart disease using velocity-selective arterial spin labeled MRI. Scientific reports. 2017;7(1):1-10.

40. Araujo Junior E, Palma-Dias R, Martins W, Reidy K, da Silva Costa F. Congenital heart disease and adverse perinatal outcome in fetuses with confirmed isolated single functioning umbilical artery. Journal of Obstetrics and Gynaecology. 2015;35(1):85-7.

41. Del Gobbo GF, Konwar C, Robinson WP. The significance of the placental genome and methylome in fetal and maternal health. Human genetics. 2019:1-14.

42. Hemberger M, Hanna CW, Dean W. Mechanisms of early placental development in mouse and humans. Nature Reviews Genetics. 2020;21(1):27-43.

43. Denis M, Enquobahrie DA, Tadesse MG, Gelaye B, Sanchez SE, Salazar M, et al. Placental genome and maternal-placental genetic interactions: a genome-wide and candidate gene association study of placental abruption. PloS one. 2014;9(12):e116346.

44. Group SCRNW. Causes of death among stillbirths. Jama. 2011;306(22):2459.

Table 1. Maternal and Stillbirth Demographic and Clinical Characteristics

\begin{tabular}{|c|c|c|c|c|}
\hline Characteristic & Pathogenic CNV & VOUS CNV & Normal CNV & P-value \\
\hline $\mathrm{N}$ & 40 & 20 & 327 & \\
\hline $\begin{array}{l}\text { Maternal age at } \\
\text { delivery, yr } \\
\text { Maternal age at } \\
\text { delivery, } \\
\text { categories }\end{array}$ & $28.9(8.0)$ & $23.6(6.1)$ & $27.4(6.4)$ & 0.012 \\
\hline$<34$ years & $29(72.5)$ & $18(90.0)$ & $277(84.7)$ & 0.105 \\
\hline [?]35 years & $11(27.5)$ & $2(10.0)$ & $50(15.3)$ & \\
\hline $\begin{array}{l}\text { Maternal } \\
\text { Body-mass-index } \\
(\mathrm{BMI}), \mathrm{kg} / \mathrm{m}^{2} \\
\text { Maternal BMI, } \\
\text { categories }\end{array}$ & $28.5(8.5)$ & $24.9(4.5)$ & $27.4(6.6)$ & 0.152 \\
\hline
\end{tabular}




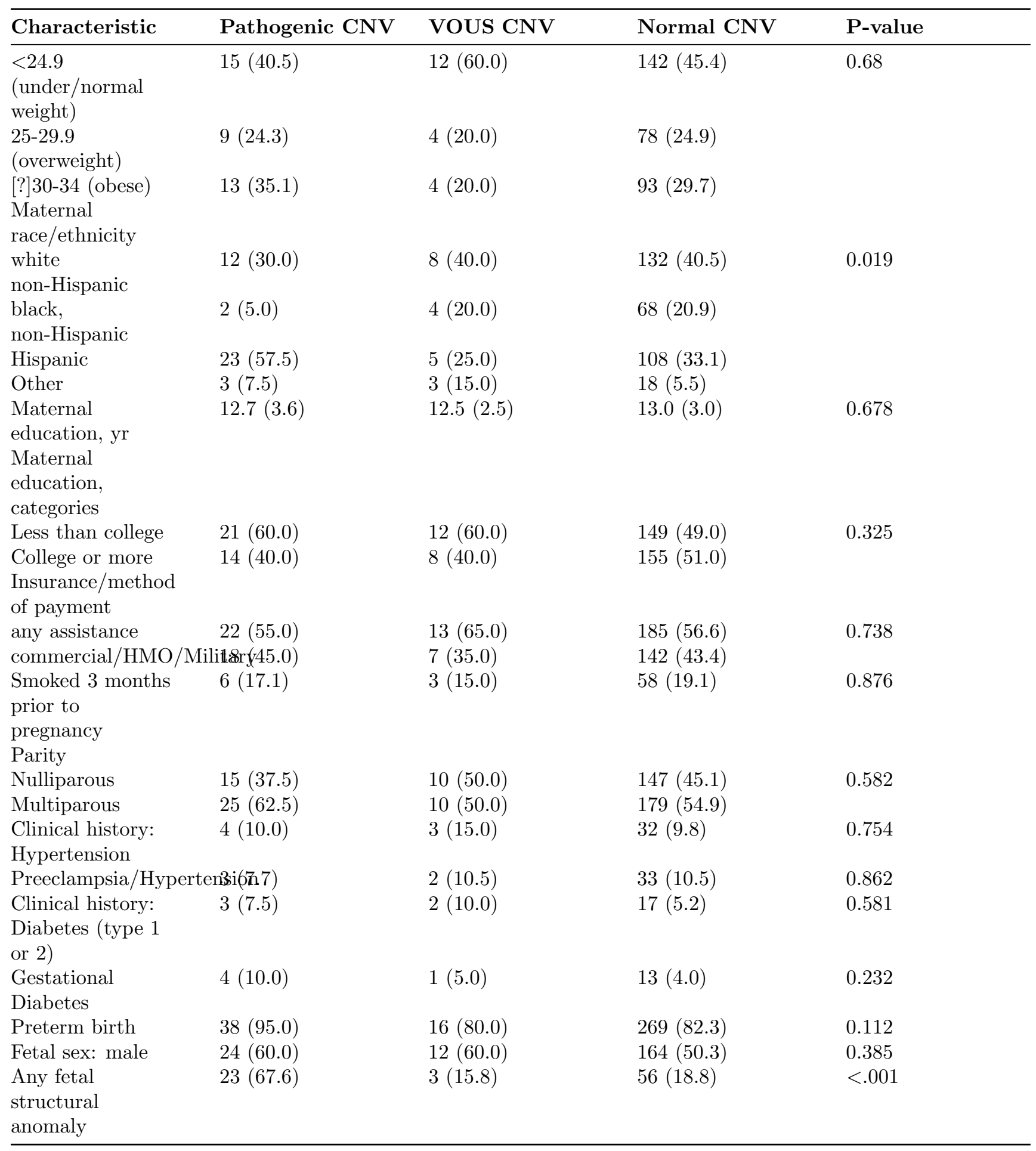

For categorical comparisons, we report frequency, percentage, and p-value from Wald chi-square test.

For comparisons of continuous measures, we report mean, standard deviation (SD), and p-value form ANOVA. 
Table 2. Specific pathogenic CNVs (excluding trisomy, monosomy, sex-chromosome and variants of unknown significance CNVs) with maternal vascular lesions in placenta of stillbirth fetuses

\begin{tabular}{lllll}
\hline Gestational age & ISCN Nomenclature $^{\mathbf{a}}$ & Chromosomal position $^{\mathbf{b}}$ & Copy number change & Genes $^{\mathbf{c}}$ \\
\hline 27 & arr 4q32.3q35.2 x1 & chr4:164762764-171448183 & DEL & AADAT, ANX \\
& arr 17p13.3 3 & chr17:150721-2961603 & DEL & YWHAE, PAF \\
23 & arr 16p13.11p12.3 & chr16:15388064-NA & DUP & ABCC1, ABCC \\
34 & & & & \\
20 & arr 17q12 x3; & chr17:37084992-38747513 & DUP & AATF, ACAC \\
27 & arr 18p11.21 x3 & chr18:13584400-14770947 & DUP & ANKRD30B, \\
37 & arr 22q11.21 x1 & chr22:19941772-22169126 & DEL & ARVCF, C22or \\
33 & arr 22q11.21 x3 & chr22:18760914-20280182 & DUP & C22orf39, CDC \\
36 & arr 22q11.21q11.23 x1 & chr22:19941772-22169126 & DEL & AIFM3, ARVC \\
\hline
\end{tabular}

a The International System for Human Cytogenetic Nomenclature for array chromosomal region

b Build 38 hg38 chromosomal position (chromosome number: position start-position end)

${ }^{\mathrm{c}}$ Copy number changes (CNVs) identified as pathogenic deletion (DEL) or duplication (DUP) CNVs

Table S1. Placental pathological lesions grouped by overarching categories.

\begin{tabular}{|c|c|}
\hline Placental Pathological Lesion Categories & Associated Lesions \\
\hline \multirow[t]{9}{*}{ Maternal vascular malperfusion } & Retroplacental hematoma/hemorrhage \\
\hline & Focal, multifocal, or diffuse parenchymal \\
\hline & infarction \\
\hline & Intraparenchymal thrombus \\
\hline & Accelerated villous maturity \\
\hline & Terminal villous hypoplasia (diffuse) \\
\hline & Increased syncytial knots (Tenney-Parker \\
\hline & changes) \\
\hline & Decidual vasculopathy \\
\hline \multirow[t]{13}{*}{ Fetal vascular malperfusion } & Marginal insertion of umbilical cord \\
\hline & Velamentous insertion of umbilical cord \\
\hline & Furcate insertion of umbilical cord \\
\hline & Single umbilical artery \\
\hline & True knot (one or more) \\
\hline & Increased cord coiling $(>3$ coils $/ 10 \mathrm{~cm})$ \\
\hline & Decreased cord coiling ([?] 3 coils $/ 10 \mathrm{~cm})$ \\
\hline & Avascular villi, focal, multifocal, or diffuse \\
\hline & Villi with stromal-vascular karyorrhexis \\
\hline & 10. Chorangiomas \\
\hline & 11. Chorangiomatosis \\
\hline & 12. Chorangiosis \\
\hline & 13. Edema (hydrops) \\
\hline \multirow[t]{2}{*}{$\begin{array}{l}\text { Inflammatory lesions involving maternal } \\
\text { compartment }\end{array}$} & $\begin{array}{l}\text { 1. Acute chorioamnionitis, placental } \\
\text { membranes }\end{array}$ \\
\hline & Acute chorioamnionitis, chronic plate \\
\hline \multirow[t]{3}{*}{ Inflammatory lesions involving fetal compartment } & Umbilical cord acute arteritis (1 vessels) \\
\hline & Umbilical cord acute arteritis ([?]2 vessels) \\
\hline & Umbilical cord acute phlebitis present \\
\hline
\end{tabular}




\begin{tabular}{ll}
\hline Placental Pathological Lesion Categories & \multicolumn{2}{l}{ Associated Lesions } \\
\hline & $4 . \quad$ Umbilical cord acute vasculitis (all vessels) \\
& present \\
& $5 . \quad$ Acute funisitis present \\
& $6 . \quad$ Chorionic plate acute vasculitis \\
& $7 . \quad$ Villitis \\
Immune/Idiopathic & Perivillous fibrin deposition Intervillous fibrin \\
& deposition Chronic intervillositis \\
\hline
\end{tabular}

Table S2. Associations of CNVs with placental pathological lesions in stillbirth

\begin{tabular}{llll}
\hline $\begin{array}{l}\text { Placental Pathological } \\
\text { Lesion Type }\end{array}$ & $\begin{array}{l}\text { Pathogenic and } \\
\text { VOUS CNV }\end{array}$ & Normal CNV* & P-value* \\
\hline $\begin{array}{l}\text { Total stillbirth } \\
\text { cases, N (\%) }\end{array}$ & $\mathbf{6 0 ( 1 5 . 5 )}$ & $\mathbf{3 2 7}(\mathbf{8 4 . 5 )}$ & \\
Maternal Vascular & $49(81.7)$ & $210(64.2)$ & 0.008 \\
Fetal Vascular & $47(78.3)$ & $252(77.1)$ & 0.829 \\
Any Vascular & $57(95.0)$ & $297(90.8)$ & 0.287 \\
Maternal Inflammatory & $15(25.0)$ & $109(33.3)$ & 0.204 \\
Fetal Inflammatory & $7(11.7)$ & $51(15.6)$ & 0.428 \\
Any Inflammatory & $17(28.3)$ & $118(36.2)$ & 0.241 \\
Immune/Idiopathic & $9(15.8)$ & $33(10.5)$ & 0.251 \\
\hline
\end{tabular}

*Values are frequency, percentage, and p-value from Wald chi-square test

Table S3 . Specific pathogenic and VOUS CNVs with maternal vascular lesions in placenta of stillbirth fetuses

\begin{tabular}{|c|c|c|c|c|}
\hline Gestational age & ISCN Nomenclature $^{a}$ & Chromosomal position ${ }^{b}$ & Total size (kilo base pairs) & Copy nun \\
\hline 27 & $\operatorname{arr} 1 \mathrm{p} 35.3 \times 1$ & $\operatorname{chr} 1: 28245805-28753654$ & 507850 & DEL \\
\hline 23 & arr $2 \mathrm{p} 16.3 \mathrm{x} 1$ & $\operatorname{chr} 2: 398808-1287541$ & 881512 & DUP \\
\hline 24 & $\operatorname{arr} 3 \mathrm{p} 21.31 \mathrm{x} 3$ & chr3:45789949-46439467 & 649517 & DUP \\
\hline 23 & $\operatorname{arr} 5 \mathrm{p} 15.2 \times 3$ & chr5:10855222-11406627 & 551405 & DUP \\
\hline 24 & arr $6 \mathrm{p} 25.1 \mathrm{p} 24.3 \mathrm{x} 3$ & chr6:6898829-7511849 & 613020 & DUP \\
\hline 23 & $\operatorname{arr} 7 \mathrm{q} 11.23 \mathrm{x} 1$ & chr7:74194985-74701057 & 506072 & DEL \\
\hline 35 & $\operatorname{arr} 7 \mathrm{p} 12.3 \times 3$ & $\operatorname{chr} 7: 48088308-48659125$ & 650946 & DUP \\
\hline 20 & $\operatorname{arr} 7 \mathrm{p} 21.1 \times 3$ & chr7:18999800-19353210 & 353410 & DUP \\
\hline 24 & arr $10 \mathrm{q} 23.3 \mathrm{x} 3$ & $\operatorname{chr10:88908456-89458227}$ & 549771 & DUP \\
\hline 23 & arr $10 \mathrm{q} 22.1 \times 3$ & chr10:70693170-71216306 & 523137 & DEL \\
\hline 24 & $\operatorname{arr} 11 \mathrm{p} 13 \mathrm{x} 3$ & chr11:33026980-33613990 & 587010 & DUP \\
\hline \multirow[t]{2}{*}{27} & arr $4 \mathrm{q} 32.3 \mathrm{q} 35.2 \mathrm{x} 1$ & chr4:164762764-171448183 & 6685419 & DEL \\
\hline & arr $17 \mathrm{p} 13.3 \times 3$ & chr17:150721-2961603 & 2810882 & DEL \\
\hline 23 & arr 16p13.11p12.3 & chr16:15388064-18463342 & 3075278 & DUP \\
\hline \multicolumn{5}{|l|}{34} \\
\hline 20 & $\operatorname{arr} 17 q 12 \times 3$ & chr17:37084992-38747513 & 1662521 & DUP \\
\hline 27 & arr $18 \mathrm{p} 11.21 \mathrm{x} 3$ & chr18:13584400-14770947 & 1186547 & DUP \\
\hline 28 & arr $19 \mathrm{q} 13.12 \times 3$ & chr19:52003118-52527157 & 524039 & DUP \\
\hline 31 & arr $19 \mathrm{q} 13.12 \times 3$ & chr19:36779213-37304888 & 525675 & DUP \\
\hline
\end{tabular}




\begin{tabular}{|c|c|c|c|c|}
\hline Gestational age & ISCN Nomenclature $^{a}$ & Chromosomal position $b$ & Total size (kilo base pairs) & Copy num \\
\hline 29 & arr 19p13.3 x3 & chr19:422237-1310137 & 887899 & DUP \\
\hline 40 & & chr19:490414-1310137 & 819722 & \\
\hline 21 & arr $21 \mathrm{q} 21.3 \times 3$ & chr21:26867843-28045871 & 1178028 & DUP \\
\hline 37 & arr $22 \mathrm{q} 11.21 \mathrm{x} 1$ & chr22:19941772-22169126 & 2227354 & DEL \\
\hline 33 & arr $22 \mathrm{q} 11.21 \mathrm{x} 3$ & chr22:18760914-20280182 & 1519268 & DUP \\
\hline 36 & arr 22q11.21q11.23 x1 & chr22:19941772-22169126 & 2227354 & DEL \\
\hline
\end{tabular}

\section{Hosted file}

Table 1.docx available at https://authorea.com/users/460174/articles/556219-copy-numbervariants-and-placental-abnormalities-in-stillborn-fetuses-a-secondary-analysis-of-thestillbirth-collaborative-research-network-study

\section{Hosted file}

Table 2.docx available at https://authorea.com/users/460174/articles/556219-copy-numbervariants-and-placental-abnormalities-in-stillborn-fetuses-a-secondary-analysis-of-thestillbirth-collaborative-research-network-study

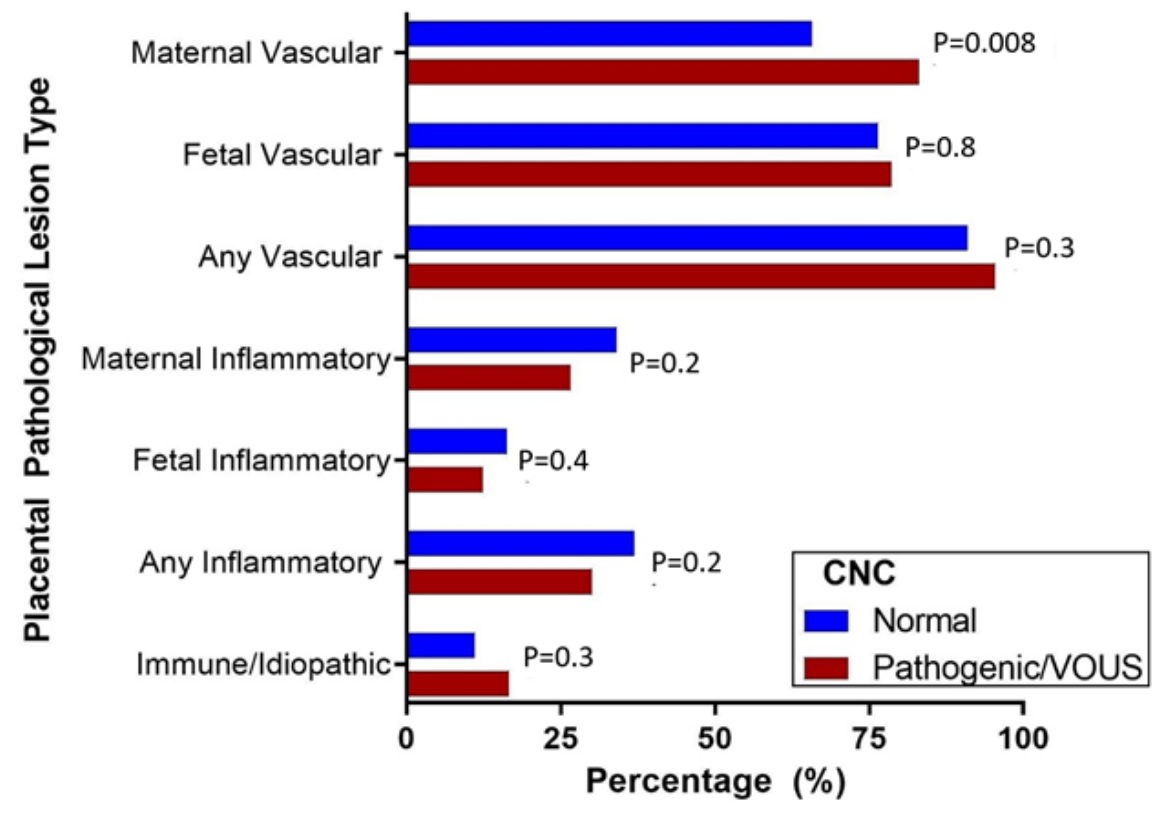

